\title{
CALDERÓN, REESCRITOR DE LOPE ${ }^{1}$
}

\author{
Germán Vega García-Luengos \\ Departamento de Literatura Española y \\ Teoría de la Literatura y Literatura Comparada \\ Universidad de Valladolid \\ Plaza del Campus, s/n \\ 47071 Valladolid. España \\ vega@let.uva.es
}

[Anuario calderoniano (ISSN: 1888-8046), 3, 2010, pp. 371-403]

De un tiempo a esta parte se ha insistido en la faceta de reescritor de quien dominara los escenarios áureos durante más de cuarenta años: «Se podría afirmar que Calderón es, por antonomasia, el dramaturgo áureo de la reescritura $»^{2}$. Son palabras de Marc Vitse en la

${ }^{1}$ Este trabajo se ha realizado en el marco del proyecto del Plan Nacional I+D FFI2008-05884-C04-04/FILO, financiado por el Ministerio de Educación y Ciencia y los Fondos Feder. Igualmente forma parte del proyecto Patrimonio teatral clásico español. Textos e instrumentos de investigación (TECE-TEI), que ha obtenido el apoyo financiero del programa Consolider-Ingenio 2010 (CSD 2009-00033), dentro del Plan Nacional de Investigación I+D+I.

${ }^{2}$ Vitse, 1998, p. 6. Balestrino y Sosa, por su parte, califican a Calderón de «reescritor empedernido» (1997, p. 104). 
«Presentación» del número 72 de Criticón, donde se recogen los trabajos presentados en un seminario celebrado en abril de 1997 en la Casa de Velázquez de Madrid, dedicado a la reescritura teatral en el Siglo de Oro. Encuentro y actas tuvieron la virtud de llamar aún más la atención sobre tan extendido y complejo fenómeno. A pesar de que dichos estudios se dedican a casos concretos, no faltan en algunos reflexiones generales sobre la materia e intentos de distinguir tipos y fases; algunos de los cuales resultarán útiles en las páginas que siguen.

\section{Tipos DE REESCRITURA CALDERONIANA}

Han sido múltiples los acercamientos a la labor de reescritura de Calderón. Una buena parte de los cuales se han fijado en lo que el propio Vitse llama auto-reescritura: de hecho los incluidos en el aludido tomo de Criticón lo son: El mayor monstruo (Ruano, 1998), La dama duende (Antonucci y Vitse, 1998). A los que se podrían añadir bastantes otros ya clásicos, como los de Ruano a La vida es sueño ${ }^{3}$, o recientes, como los que constituyeron las tesis doctorales, a las que deseamos una pronta publicación, de María José Caamaño, sobre el Mayor monstruo del mundo (2006); de Covadonga Romero, sobre La señora $y$ la criada y El acaso y el error (2007); y de Fernando Rodríguez-Gallego, sobre Judas Macabeo y El astrólogo fingido (2009) ${ }^{4}$.

La mayoría de los casos corresponden a la operación que Ruano llama «reelaboración», que es la que «pule, perfecciona, afina y modifica un texto teatral para crear una nueva versión, y puede ser llevada a cabo por el propio dramaturgo, como hace, por ejemplo, Calderón con su La vida es sueño, o por otro profesional de la Comedia» (1998, p. 35). Pero la auto-reescritura calderoniana puede ser de otros tipos. Tan acusada como esta reelaboración es la «reutilización», consistente — también en palabras de Ruano- «en el aprovechamiento de una

${ }^{3}$ Ver especialmente Ruano, 1992.

${ }^{4}$ En este último trabajo se ofrece un buen estado de la cuestión en el largo capítulo dedicado a estudiar "el problema de las versiones variantes», como punto de partida para tomar sus propias decisiones sobre las piezas que le corresponde editar. Además del rigor con que se ha llevado a cabo, este panorama tiene la ventaja de su posterioridad con respecto a otros, lo que le ha permitido asumir lo mucho que se ha escrito sobre reescritura calderoniana en tiempos recientes. 
escena o pasaje textual en diferentes piezas teatrales, como ocurre con los autos sacramentales de Calderón...» (1998, pp. 35-36). Su teatro está plagado de manifestaciones de este fenómeno. Sería muy interesante - y hoy tenemos los medios para ello- establecer un atlas de tales recurrencias, para poder diferenciar aquellas de amplio recorrido, que aparecen a lo largo de toda su dilatada trayectoria, de aquellas otras que afectan a los textos cercanos cronológicamente. Además de lo que esto pueda decir de su arte dramático, proporcionaría utilísimas herramientas para la atribución y la datación de obras con problemas en este sentido, con que completar la eficacia de otras que se han venido explotando tradicionalmente para estos fines, como el análisis estrófico. He tenido oportunidad de comprobar la rentabilidad de estas reutilizaciones en el empeño de buscar autor y fecha a una serie de piezas cuya relación con el dramaturgo es necesario aclarar. Y aún manejaré algunos testimonios más en el presente estudio, a pesar de que este no tratará del Calderón de la auto-reescritura principalmente, sino del de la hetero-reescritura ${ }^{5}$.

El trabajo de referencia en este campo es el de Sloman (1969), en el que analiza con detenimiento ocho comedias con fuentes en obras de otros escritores o en las que él ha colaborado:

\section{Comedia de Calderón}

El médico de su honra

Las armas de la hermosura

Los cabellos de Absalón

El mayor encanto amor

La niña Gómez Arias

\section{Comedia fuente}

El médico de su honra (atribuida a Lope de Vega) El privilegio de las mujeres (atribuida a Calderón, Montalbán y Coello $)^{6}$

La venganza de Tamar (Tirso de Molina) Polifemo y Circe (Mira, Montalbán, Calderón)

La niña de Gómez Arias (Luis Vélez de Guevara)

5 También este término es utilizado por Vitse, 1998, p. 6.

${ }^{6}$ Una propuesta diferente de la autoría de esta comedia en colaboración puede verse en Vega García-Luengos, 2009, pp. 478-487. 
El príncipe constante

El alcalde de Zalamea

La vida es sueño
La fortuna adversa del Infante D. Fernando de Portugal

(atribuida a Lope de Vega)

El alcalde de Zalamea

(atribuida a Lope de Vega)

Yerros de naturaleza y aciertos de la fortuna (Coello, Calderón)

En las páginas de introducción, señala Sloman otros casos de reescritura que él mismo u otros han notado. Así, el de El jardín de Falerina, que procedería de la pieza homónima de Rojas, Coello y Calderón ${ }^{7}$; Saber del mal y el bien, de La mudanza de la fortuna y sucesos de don Beltrán de Aragón, de Lope de Vega ${ }^{8}$; La selva confusa, de una supuesta obra del mismo título atribuida a Lope de Vega9; El encanto sin encanto, de Amar por señas, de Tirso de Molina ${ }^{10}$; El mayor monstruo del mundo, de una supuesta comedia de otro autor con la misma denominación ${ }^{11}$.

\section{Sobre las Relaciones de Lope y CaLderón}

El Calderón hetero-reescritor que interesa en este trabajo es el que toma como modelo piezas de Lope. Se trataría, pues, de acercarse a un aspecto fundamental —en lo humano y, sobre todo, en lo literario- de la relación entre estos dos "monstruos de naturaleza», ostentadores consecutivos e indiscutibles de la monarquía cómica española, capítulo fundamental de su pasado cultural. No le falta interés, ni morbo, al intento: desde la perspectiva de Calderón, sobre quien tan-

7 Sloman, 1969, p. 13 n. 1.

${ }^{8}$ Sloman atribuye el apunte de esta relación a Fitzmaurice-Kelly, que lo Habría hecho en un suplemento de la Encyclopaedia Britannica (11 ${ }^{\mathrm{a}}$ ed., 1910-1911). De ella nos ocuparemos con detalle en el presente trabajo.

${ }^{9}$ Apuntado por Heaton, 1929, y contradicho por Sloman, Morley-Bruerton, etc. como tendremos oportunidad de ver más adelante.

${ }^{10}$ Señalada también por Fitzmaurice-Kelly en el ya mencionado suplemento de la Encyclopaedia Brtannica (11 $1^{a}$ ed., 1910-1911).

${ }^{11}$ H. C. Heaton, 1951, apuntó que en el texto de la edición de 1653 Calderón pudo refundir una obra previa de otro dramaturgo, representada en las fiestas de Yepes. Tal teoría fue rechazada por Sloman, 1952b. 
to se ha escrito acerca del enfrentamiento contra el padre biológico en sus obras ${ }^{12}$, no puede por menos que seducirnos la idea de atisbar cuál sería su actitud con quien era, reconociéralo o no, su padre teatral.

Ambos compartieron un tiempo de vida y escritura no menor de 15 años: desde al menos 1620 (cuando Calderón contaba con 20 y Lope con 58) a 1635, años importantísimos para el teatro español ${ }^{13}$. Siempre se ha dado por supuesta una relación de animadversión entre ellos. Sin embargo, a diferencia de lo que ocurre con las que Lope mantuvo con Cervantes, Góngora o Pellicer, donde los testimonios conservados de sus enfrentamientos son explícitos y contundentes, de la presunta rivalidad entre los dos grandes de la escena barroca no nos han llegado muestras de este tipo; sino que se han deducido de supuestas alusiones sutiles de los escritos respectivos de ambos o de episodios en que se han podido ver involucrados ${ }^{14}$. Pero las alusiones explícitas no autorizan a pensar en una mala relación ${ }^{15}$. Sin embargo, como filólogos, interesan, sobre todo, las relaciones entre textos. Hacia Calderón como reescritor de Lope apunta nuestro objetivo hoy, sin desdeñar que existan en la otra dirección ${ }^{16}$.

Es claro que Lope estuvo molesto con los dramaturgos jóvenes, lo que apunta ya en textos desde 1620 y se hace más denso a partir de 1630. Puede deducirse de sus palabras, aunque, como ha apuntado Pedraza, no le guste o no quiera mostrarlo abiertamente (2001, p. 843), "para no agravar — ahora la idea es de Rozas - sus malas relaciones con Palacio donde ellos eran bien vistos y queridos» (1990, p. 373).

12 Un replanteamiento de distintos aspectos de esta cuestión puede verse en Pedraza, 2000, pp. 18-22.

13 A estas relaciones y al periodo se han acercado con acierto, entre otros, los trabajos de Rozas (1990), Profeti (1997), Pedraza (2001), González Cañal (2002).

14 En dos se insiste especialmente: la entrada violenta de Calderón en el convento de las Trinitarias en 1629, donde estaba la hija de Lope; o la ausencia de Calderón en el tomo de la Fama póstuma de Lope, coordinado por Pérez de Montalbán en 1636.

${ }^{15}$ Ver Pedraza, 2001, pp. 846-848.

16 Sin llegar a la categoría de reescritura, por su escasa dimensión, sí que se han apuntado en piezas de Lope indicios de un conocimiento previo de obras de Calderón. Lo ha hecho Oleza con respecto a La boba para los otros y discreta para sí, que acusaría paralelismos con La vida es sueño (Oleza, 2003, p. 619). Tras adelantar convenientemente la fecha de escritura de esta última comedia, todo apunta a que en ella está pensando Lope cuando escribe el famoso pasaje de El castigo sin venganza. 
Ni le gusta hacer ostentación, ni lo singulariza con claridad en tal o cual autor. Conociendo a Lope $-\mathrm{y}$ pocos escritores se empeñaron tanto en dejar noticia de si en sus obras-, la lógica nos dice que su molestia debería ser directamente proporcional a los éxitos del competidor: pero en ningún momento nombra abiertamente a Calderón. Ha sido Rozas quien con más ahínco ha buscado señales que pongan de manifiesto esta animadversión particular. Así, interpreta como alusión al dramaturgo estos versos de La Dorotea:

No mires los que salen, ni barco nuevo envidies, porque le adornen jarcias y velas le entapicen ${ }^{17}$.

Que sería gemela a la famosa mención de los «pájaros nuevos» de la Égloga Amarilis:

Canta y darás envidia a los pájaros nuevos, que fastidia el canto de los dulces ruiseñores ${ }^{18}$.

Para Rozas, el «barco nuevo» «es sospechoso de aludir al segundo apellido de Calderón de la Barca y acorde con la forma sibilina con que satiriza en su vejez a los jóvenes» (1990, p. 373). También cree que se refieren a su teatro estos versos de la Epístola a Claudio:

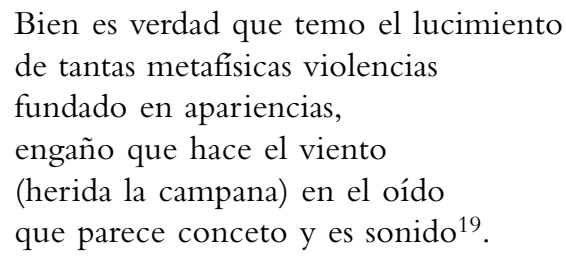

Calderón sería el receptor "privilegiado» de dos manifiestos de Lope: el teórico de la Epístola a Claudio y el práctico El castigo sin venganza (Rozas, 1990, p. 374).

17 En Rozas, 1990, p. 372.

18 En González Cañal, 2002, p. 152.

19 En Rozas, 1990, p. 373. 
De su enfrentamiento con los dramaturgos más jóvenes hay huellas anteriores a su ciclo de senectute. En el prólogo «El Teatro a los letores» de la Décima quinta parte (1621) defiende el estilo de siempre, la lengua "antigua» en que están escritas las doce piezas que incluye el libro, frente al de los «poetas deste año» y acaba con la reivindicación de su propia importancia en la historia de la comedia nueva:

Lea, pues, el desapasionado el libro, el que no quiere con una comedia sola escurecer novecientas y veinte y siete, que este autor ha escrito, contando las que se llaman autos; perdonando los yerros que por haber corrido por tantas manos, serán forzosos. Y el que ha tan poco que las escribe, no sea ingrato a lo que en su vida acertara sin esta carta de navegar ${ }^{20}$

La idea recurrente en esta guerra contra los «pájaros nuevos» es que él ha hecho posible el teatro del que viven los que le critican. Lope se consideraba el principal responsable de la fórmula que se había impuesto en los escenarios, gracias a su esfuerzo y perspicacia. Los jóvenes, en cambio, se habían encontrado el camino allanado. Este planteamiento está muy activo en su Epístola a Claudio, donde, aprovechando la idea atribuida a Bernardo de Chartres, reclama su categoría de "gigante» sobre cuyos hombros se han aupado los «enanos» triunfantes en la corte:
Cuando un concepto a todas luces suena, lo que ven por sí mismos reconozco; pero también conozco cuando es la vista ajena: que no ha de dar la de un enano asombro si le lleva un gigante sobre el hombro. ${ }^{21}$

Muy ligada con esta idea se encuentra otra que aparece en la Epístola y en otras obras de esos años: la sustracción de sus piezas por otros poetas, que además le critican:

Sin esta confusión, como renuevos, en quien su imagen verde planta imprime,

${ }^{20}$ Lope de Vega, Comedias escogidas, IV, pp. XXIV-XXV.

21 En Pedraza, 2001, pp. 843-844. 


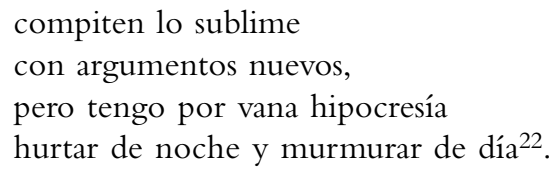

Y Lope tenía motivos para creerlo así. Muy probablemente por lo que se refiere a todos los dramaturgos nuevos y, con seguridad, a Calderón, como mostrarán las páginas que siguen.

LA IDENTIFICACión DE APROVECHAMIENTOS DE OBRAS DE LOPE POR CALDERÓN

Sobre la presencia de romances - a veces, sonetos - de Lope en las piezas de Calderón han apuntado testimonios J. C. Torres (1999) y F. Pedraza (2001, pp. 847-849). Sus versos se han incorporado con más o menos conciencia en obras como Dar tiempo al tiempo, El conde Lucanor, No hay cosa como callar, Céfalo y Pocris (especialmente), Para vencer amor (el propio título remite al soneto II de las Rimas), La púrpura de la rosa. Tiene la impresión Pedraza, tras apuntar los casos que se acaban de señalar, que «Lope fue una referencia familiar, repetida no siempre de forma consciente» (2001, p. 849).

Pero al punto que queremos llegar es al de la reescritura de sus comedias. La siguiente tabla da cuenta sucinta, por orden alfabético, de los nueve casos que distintos estudiosos han aducido hasta la fecha:

Comedia de Calderón

El alcalde de Zalamea

Amor, honor y poder

La fingida Arcadia

(colaboración: acto I de Calderón)

\section{COMEDia Fuente}

El alcalde de Zalamea

(atribuida a Lope de Vega)

El Rey por trueque

(atribuida a Lope de Vega)

La Arcadia

(Lope de Vega)

La fingida Arcadia

(Tirso de Molina)

22 En González Cañal, 2002, p. 157. 


$\begin{array}{ll}\text { El maestro de danzar } & \begin{array}{l}\text { El maestro de danzar } \\ \text { (Lope de Vega) }\end{array} \\ \text { El médico de su honra } & \begin{array}{l}\text { El médico de su honra } \\ \text { (atribuida a Lope de Vega) }\end{array} \\ \text { La fortuna adversa del Infante D. } \\ \text { Fernando de Portugal } \\ \text { (atribuida a Lope de Vega) } \\ \text { La Margarita preciosa } \\ \text { La Margarita preciosa } \\ \text { (colaboración: Zabaleta, } & \text { (auto de Lope de Vega) } \\ \text { Cáncer, Calderón) } & \text { Las mudanzas de fortuna y sucesos de } \\ \text { Saber del mal } y \text { el bien } & \text { don Beltrán de Aragón } \\ & \text { (Lope de Vega) } \\ & \text { La selva confusa } \\ \text { La selva confusa } & \text { (atribuida a Lope de Vega) }\end{array}$

Como el presente trabajo trata de determinar sobre un corpus seguro las características del encuentro de las dos grandes figuras de la dramaturgia áurea, el primer filtro debería dejar fuera las comedias en colaboración — La fingida Arcadia y La Margarita preciosa-, por no poder asegurar que fuese Calderón quien tuviera la voluntad de aprovecharse de un texto previo de Lope, ni que fuera el responsable de los contactos textuales concretos ${ }^{23}$.

Que La selva confusa sea una refundición calderoniana de una obra de Lope de Vega con el mismo título fue planteado por H. C. Heaton (1929). La pieza apareció en la Parte XXIV de Lope [y otros] (Zaragoza, D. Dormer-J. Ginobart, 1633), con el título de Selvas y bosques de amor, y en la Parte XXVII de Lope (Barcelona, Sebastián de Cormellas, 1633 [Sevilla, Manuel de Sande]), con el de La selva confusa. También se conserva un autógrafo de Calderón, cuyo texto Heaton interpretó como refundición de la obra previa de Lope, que identifica con la que se menciona como El desdichado en las listas del Peregrino. Sloman refutó contundentemente esta teoría (1952a): en realidad, y a pesar de las variantes, los tres textos corresponden a una misma comedia (como ya vio González Palencia en su edición del tomo IX, 1930, de las

${ }^{23}$ La tarea de cada dramaturgo en las obras en colaboración puede no limitarse a la porción asignada, normalmente una jornada, sino que cabe la intervención en las de sus colegas. Ver Alviti, 2006, p. 168. 
Obras de Lope de Vega de la Real Academia Española, nueva edición), cuya versión original identificó con el texto del autógrafo, mientras que las ediciones ofrecerían textos abreviados para la representación ${ }^{24}$. Como ha mostrado D. W. Cruickshank, La selva confusa es una de las cinco comedias de Calderón que antes de que se publicara su Parte I (1636) habían aparecido en un total de siete ediciones a nombre de Lope de Vega ${ }^{25}$.

De los seis casos restantes, sorprendentemente, pero no parece que se pueda considerar fortuito, en cuatro los textos en que se habría basado Calderón son de atribución dudosa a Lope. Entre ellas están dos de las consideradas como obras maestras: El alcalde de Zalamea y El médico de su honra. Es muy difícil que los supuestos modelos - que curiosamente se denominan igual que las piezas de Calderón- sean de Lope de Vega. Así lo dictaminan Morley y Bruerton, que hoy por hoy disponen de la patente del mejor invento para poner fechas y marchamos de autenticidad a las comedias del Fénix: su análisis estrófico ${ }^{26}$. Ambas han merecido sendas ediciones cuidadosas junto con las obras de Calderón respectivas por parte de J. M. Escudero (1998) y A. Armendáriz (2007), que tampoco se decantan por la atribución a Lope.

Amor, honor y poder se basaría en El Rey por trueque, que, aunque atribuida a Lope de Vega en un manuscrito con letra del siglo XVII de la Biblioteca Nacional (Ms. 14.928), ni a Cotarelo, que la editó en el tomo II (1916) de la colección Obras de Lope de Vega de la Real Academia Española (nueva edición), ni a Morley y Bruerton les parece suya ${ }^{27}$.

La relación entre La fortuna adversa del Infante D. Fernando de Portugal y El príncipe constante es estudiada con detalle por Sloman (1969, pp.

${ }^{24}$ Una crónica ajustada de las sucesivas interpretaciones puede verse en Morley y Bruerton, 1968, pp. 555-557. Eric Coenen está realizando una edición crítica de la obra.

${ }^{25}$ Cruickshank, 2000, p. 12. Las otras cuatro serían Amor, honor y poder (con el título de La industria contra el poder), La devoción de la cruz (con el de La cruz en la se pultura), La puente de Mantible y La vida es sueño.

${ }^{26}$ Ver el análisis de El alcalde de Zalamea en Morley y Bruerton, 1968, pp. 411412; y el de El médico de su honra en pp. 509-510.

${ }^{27}$ Morley y Bruerton, 1968, p. 549. En su análisis también hacen constar las opiniones contrarias de Hämel y Homero Arjona. 
188-216), sin plantearse si la fuente es obra auténtica de Lope. A Bonilla (1933), su descubridor en el tomo 132 de la biblioteca de Osuna, que hoy se custodia en la Biblioteca de la Universidad de California en Berkeley, le parece que $s^{28}$. Por su parte, Morley y Bruerton, que consideran que el texto es malo y que faltan versos (1968, pp. 467-468), no se deciden a atribuírsela, porque si fuera de Lope sería del periodo 1597-1603, cuando hasta 1605 no se fija una técnica métrica que permita diferenciarlo de otros dramaturgos contemporáneos ${ }^{29}$.

Quedan dos casos, cuyas supuestas fuentes lopistas no parecen plantear ningún problema de atribución. El maestro de danzar de Lope es considerado por González Cañal como «precedente» de la de Calderón del mismo título (2002, p. 157). El supuesto modelo correspondería a una fase temprana de la escritura dramática del Fénix, pues la escribió en enero de 1594, tal como consta en un manuscrito conservado, que es copia del autógrafo; fue bastante tiempo después publicada en la Parte III de la colección de Nuevas escogidas (Madrid, Melchor Sánchez-Joseph Muñoz Barma, 1653). La comedia de Calderón se publicó dentro de la Parte IV (1664) y se habría escrito hacia 1651-1652, según el estudio métrico de Hilborn (1938, pp. 57 y 62). Barclay (1971) dedicó un estudio conjunto a las dos piezas, pero su interés no estaba en lo relacionado con la reescritura sino en valerse de ellas para describir los bailes que se mencionan y mostrar cómo supuestamente ha cambiado la consideración de la danza en la corte entre 1594 y 1650. Aparte del título, solo consigna una semejanza entre ambas: «el hidalgo se finge maestro de danzar para conquistar a su amada» (Barclay, 1971, p. 77). Lo demás son diferencias. D. W. Cruickshank, por su parte, en su reciente y espléndido libro sobre Calderón asevera de su obra: "What is certain that the play has nothing in common with Lope's El maestro de danzan (2009, p. 308). Es cierto que las coincidencias argumentales son mínimas, y algunas de ellas probablemente no buscadas; sin embargo, la estrecha coincidencia de los títulos y el que la pieza primera se publicara en 1653, cuando podía no estar aún escrita la segunda - la fecha apuntada más arriba se deduce del análisis métrico, cuyos resultados no pueden considerarse exactos-

28 Bonilla y San Martín, «Sobre un tomo perdido de Lope de Vega», 1933.

${ }^{29}$ Ver Morley y Bruerton, 1968, p. 452. 
permiten pensar que de ella tomó Calderón el título y la idea de que su galán se hiciera pasar por maestro de baile para entrar a la casa de la dama. Ardid, por otra parte, nada original en lo sustancial: son bastantes los galanes y criados que se hacen pasar por maestros de danza, o de otra disciplina especialmente de latín, para colarse en las casas de las damas en las comedias del siglo XVII. Lo demás es diferente: tipología genérica, marco geográfico, argumento, personajes, etc. A esas alturas de su historia a Calderón ya no le movía ningún interés de confrontar su arte con el de Lope, que llevaba 15 años muerto, a diferencia de lo que ocurriría una veintena de años antes, cuando ambos vivían y creaban, tal como se intentará mostrar en seguida. Su Maestro de danzar bien pudo ser pensado como homenaje al lejano Lope. Sin desdeñar la posibilidad de que quisiera utilizarlo como reclamo comercial.

\section{UN ÚNICO CASO DESCUIDADO: SABER DEL MAL Y EL BIEN}

Y a la altura de la historia en que se encuentra el presente estudio, nos hemos quedado con una sola comedia entre las nueve de las que se habían apuntado fuentes con posibilidades de ser de Lope: Saber del mal y el bien, de la que alguien alguna vez apuntó su relación con Las mudanzas de fortuna y sucesos de don Beltrán de Aragón. Todo parece indicar que el origen de ese dato está en Durán (Catálogo, s. a.), sin que ni él ni nadie de los que después lo han consignado pasaran de su mención escueta ${ }^{30}$. Tampoco consiguieron que repararan en ella aquellos investigadores que podrían haberlo explotado oportunamente en sus trabajos. Son los casos de quienes se han acercado recientemente a las piezas involucradas para editarlas. La de Las mudanzas ha estado a cargo de G. Pontón, bajo los auspicios del proyecto Prolope,

30 Todo apunta a que la secuencia ha sido esta: Durán ([Catálogo], s. a.) > Paz y Melia (1934, núm. 3220 [1 ${ }^{a}$ ed. 1899]) > Fitzmaurice-Kelly $(1910-1911)>$ Sloman (1969, p. 14) > González Cañal (2002, p. 157). Recientemente, Cruickshank (2009, p. 362 n. 15) me ha atribuido el haber señalado la fuente lopista de la comedia de Calderón (Vega, 2005, p. 260). Lo cierto es que cuando elaboré aquel trabajo ignoraba el apunte que Durán había puesto en circulación, y creía haber sido el primero en dar con esa relación (eso sí, cuando buscaba otra cosa, como ocurre casi siempre en estos lances). 
ya que fue incluida en la Parte III de Lope [y otros], y publicada recientemente con los otros dos textos del Fénix que hay en dicho volumen (2002, pp. 253-365). La de Saber del mal y el bien la llevó a cabo L. Iglesias, junto con el resto de las piezas que componen la Primera parte de Calderón (2006), dentro del proyecto de edición de las obras completas del escritor para la Biblioteca Castro ${ }^{31}$.

Este caso ignorado por lopistas y calderonistas es diferente a los considerados hasta ahora: para empezar, las dos pertenecen con seguridad a quienes se atribuyen (no como la mayoría de las contempladas) y presentan claros y múltiples puntos de contacto (no como El maestro de danzar, que apenas pasa del título). Sabemos también cuándo fueron escritas y publicadas. La fecha de escritura de Las mudanzas estaría entre 1597 y 1608, según Morley y Bruerton (1968, p. 365); para Pontón, su editor moderno, entre 1607 y 1608 . Fue publicada en 1612 junto con otras dos obras de Lope y nueve de otros dramaturgos en la fraudulenta Parte III. Saber del mal la representó Roque de Figueroa en el Prado y recibió el pago correspondiente en marzo de $1628^{32}$. Es decir, que la pieza de Calderón podría dar por buenas las quejas de Lope en la Epístola a Claudio y en otros lugares, cuando señala que los poetas jóvenes no solo tienen el camino de la comedia nueva abierto gracias a su esfuerzo, sino que le hurtan sus obras.

Para intentar conocer los móviles y los efectos de ese «hurto» hay que estudiarlo con detenimiento. Dichos efectos podrían exonerar a Calderón del delito. Ya sabemos cómo se consigue esto en literatura. La explicación más contundente al respecto se atribuye a Victor Hugo: «en literatura el robo solamente es disculpable cuando va acompañado del asesinato"; es decir, cuando se logra un producto superador del modelo y con autonomía artística. Para empezar, debe decirse que no hay ni un solo verso de la primera obra que haya pasado a la segunda.

La consideración de los puntos de contacto principales entre ambas piezas, al tiempo que refrescará sus argumentos, pondrá en evidencia la estrecha relación que mantienen:

Un valido bueno y leal (Beltrán de Aragón, en la comedia de Lope / el Conde Pedro de Lara, en la de Calderón) de un rey (Alfonso de

31 También ha merecido un estudio textual de Novo, 2002.

32 Shergold y Varey, 1961, p. 284. 
Aragón / Alfonso de Castilla) protege a un hombre desvalido (Juan Abarca / Álvaro de Viseo), que es en realidad un gran noble que ha tenido que huir de su reino (Aragón / Portugal). Lo eleva socialmente y ambos se comprometen a ser fieles amigos.

Dos envidiosos de la corte (Feliciano y Bernardo / Ordoño e Íñigo) a través de artimañas (calumnias verbales / carta) enemistan al rey con el valido, que debe marchar fuera.

El amigo (Juan Abarca / Álvaro de Viseo) es elevado al puesto de privado. Sus intentos por las buenas de restituir al caído en desgracia en el favor del rey fracasan porque este le prohíbe hablar en su favor.

En ambas comedias los amigos recelan el uno del otro al malinterpretar situaciones.

Al final se conoce la verdad y es restaurado el caído. Privado y amigo casan con las dos damas.

También el enredo amoroso asocia ambas obras. En la de Lope el monarca, que está enamorado de doña Leonor, le pide a don Juan Abarca, al que ha nombrado valido, que logre que le favorezca como prueba de su lealtad. También con la misma intención de probarlo, en la pieza de Calderón el rey le pide a Álvaro de Viseo que le consiga a Hipólita, de la que ambos están enamorados, y que es hermana del Conde Pedro de Lara.

Las damas ofrecen más paralelismos. En ambos textos una de ellas (Elvira / Hipólita) es hermana de uno de los protagonistas (Juan Abarca / Pedro de Lara), quien, malinterpretando ciertos indicios relacionados con ella, llega a sospechar que el amigo le ha traicionado y deshonrado.

Se trata, pues, de dos comedias de privanza y fortuna bifronte, que, como siempre ocurre con este espécimen de obra histórica, animan a los investigadores a asociarlas con la realidad política del momento, en que Lerma u Olivares se encuentran al frente de los destinos de España. El último en manifestarse en este sentido ha sido Cruickshank, quien no ha dudado en establecer una relación directa y crítica de Saber del mal con la privanza del Conde-duque. Según el estudioso, pertenece a una fase en la que Calderón estaría aprendiendo a hablar al rey, "that is, of making unpalatable facts palatable, of presenting constructive criticism without seeming disloyal» ${ }^{33}$. Apuntaría, entre otras cosas, que el

33 Cruickshank, 2009, p. 97. 
valido no es indispensable. Confieso mi dificultad para entender cómo el rey y Olivares podían aceptar estas críticas nada banales, y cómo Calderón, con ellas podía arriesgarse tanto a fracasar en sus deseos de triunfar en aquella corte, lo que a la postre quedará reflejado en la obtención del hábito de Santiago en 1636.

Pero en este momento lo que interesa es comentar las características de la reescritura calderoniana. El dramaturgo se ha aprovechado del tema y motivos principales, del juego básico de personajes - tanto por lo que se refiere a su identidad como a sus relaciones-, de resortes de la acción, etc.

Si hay un término que pueda definir las operaciones realizadas es el de concentración. Las múltiples posibilidades ofrecidas por la comedia de Lope en los distintos niveles se condensan: los personajes pasan de 17 a 11; los lances se reducen; de un desarrollo lineal de la acción se pasa a una mayor trabazón de los distintos segmentos, que cobran una mayor significación, al aumentar la de cada elemento interviniente en ellos, tanto verbales como escénicos.

En efecto, también la propuesta espectacular ofrece diferencias. Lope encomienda lo que quiere decir en buena medida a las palabras, mientras que Calderón es más proclive a implicar el juego escénico en ese cometido. Para ilustrarlo me limitaré a un solo episodio, pero bien expresivo: el de la primera aparición en escena de los desvalidos, que habrán de convertirse en validos, Juan Abarca y Álvaro de Viseo. El primero lo hace empujado, entre voces, por uno de los cortesanos que lo ha encontrado merodeando en Palacio:

FELICIANO ¡Salid allá!

DON JUAN ¡Poco a poco!

FELICIANO ¡Despejad la sala luego!

DON JUAN Que me tratéis bien os ruego...

(vv. 139-141)

Álvaro de Viseo, en cambio, lo hace como tantos otros personajes calderonianos, despeñándose al comienzo de una jornada (la primera, normalmente). Qué mejor manera de llamar la atención del público, por un lado, y, por otro, de significar el extremo más bajo de la rueda a la que ha llegado su fortuna, desde el que empezar a subir: 
Don Álvaro Viseo, muy herido y ensangrentado, baja despeñándose de un monte a los pies de las damas y con un pan en las manos y la espada desnuda. (p. 581)

El móvil principal de la propuesta de Calderón no parece que fuera el ahorro de esfuerzo en discurrir un argumento a la imaginación ni de tiempo en la elaboración, sino que debió de guiarle su interés por acomodar el modelo a nuevos presupuestos, con pretensiones de mejorarlo y, seguramente, con un cierto empeño por medir sus fuerzas con las del Fénix en su mismo terreno.

RELACIONES Y REUTILIZACIONES ENTRE SABER DEL MAL Y EL BIEN Y CÓMO SE COMUNICAN DOS ESTRELLAS CONTRARIAS

Saber del mal es una comedia inequívocamente ligada a Las mudanzas, que le ha servido de fuente, estímulo y emulación. Pero también - y como no podía ser menos, dada la forma de trabajar de Calderón- está muy conectada a otras piezas del propio dramaturgo, con las que comparte lances, soluciones escénicas, imágenes, expresiones. Es normal que esto ocurra especialmente entre las escritas en fechas cercanas.

De todas sus obras, o con posibilidades de que lo sean, con las que Saber del mal establece una red de correspondencias, la palma se la lleva, sin duda, la titulada Cómo se comunican dos estrellas contrarias, inserta en la falsa Parte $V(1677)$ y rechazada como auténtica por el propio Calderón y por los calderonistas, desde su contemporáneo Vera Tassis hasta hoy. No obstante, en algunos trabajos previos he apuntado las razones por las que pienso que él es el principal candidato para la autoría ${ }^{34}$.

A medida que he ido considerando con mirada microscópica sus versos, con el fin de preparar su edición crítica, me he pertrechado de nuevas razones de índole estilística para acercársela a don Pedro. A ellas se ha venido a sumar un apoyo externo, que incide sobre lo que se considera uno de los principales escollos para la atribución: el que el dramaturgo no solo no la incluyera en las listas de comedias auténti-

${ }^{34}$ Vega García-Luengos, 2005 y 2006. Mi propuesta ha encontrado eco favorable en los últimos trabajos de Cruickshank, 2009, p. 69 y Coenen, 2009, p. 131 n. 16. 
cas, la de Carlos II (o Marañón) y la de Veragua, sino que la rechazara explícitamente en la primera de esas relaciones ${ }^{35}$. Dicho respaldo lo acaba de proporcionar Cruickshank (2009, p. 68), al sacar a la luz lo que dice Juan Isidro Fajardo en su inédita Disertación sobre los autos sacramentales de don Pedro Calderón de la Barca, fechada en 1718, con referencia a los autos de El divino Jasón y La cena del rey Baltasar:

$\mathrm{Y}$ aunque se duda sean suyos, creo que estos autos son de los primeros que hizo, y que después negó, o enmendó; pues en las comedias que imprimió siendo mozo con el nombre de don Pedro Calderón y Riaño hizo lo mismo, declarando no eran suyas las que tenían este nombre; y que solo conocía por propias las que estaban con el de don Pedro Calderón de la Barca (BMP, Ms. 209, fols. 8r-8v).

Este testimonio cercano al tiempo del escritor debe añadirse a las reflexiones que he efectuado en un estudio reciente sobre los olvidos y rechazos de don Pedro en las listas antedichas (Vega García-Luengos, 2008, pp. 250-254).

Las acciones de Saber del mal y Cómo se comunican están localizadas en la España medieval. Para empezar, y nunca mejor dicho, los comienzos respectivos presentan situaciones paralelas: sus damas protagonistas femeninas comparten sus penas con otros personajes en el campo cuando irrumpe es escena don Álvaro de Viseo o se percata de que está en ella don Enrique de Borgoña, los galanes principales correspondientes, que se encuentran malheridos ${ }^{36}$. Expresan ideas y sentimientos análogos, con medios expresivos paralelos. Así, incurren en imágenes semejantes al hablar de la sangre en las flores o de las funciones de sepulcro-pirámide-monumento que desempeñan los elementos naturales, como se puede apreciar en los fragmentos siguientes. Dice Hipólita en Saber del mal:

Hombre infelice, a quien pone

la fortuna en tal estado,

que en las entrañas de un roble

35 En Wilson, 1962, p. 98.

36 Algunos de los paralelismos que siguen ya se han aducido en Vega GarcíaLuengos, 2005, pp. 252 y ss. 
es tu sepulcro una peña

y tu pirámide un monte... ${ }^{37}$ (p. 582)

Lo que tiene su correlato en los versos iniciales de Cómo se comunican:

Démosle sepultura

en las entrañas desta peña dura,

$\mathrm{y}$ con funestos ramos

el pálido cadáver encubramos,

a cuyo horror sangriento,

será el monte sepulcro y monumento ${ }^{38}$. (vv. 1-6)

No están lejos estos versos de estos otros de La vida es sueño, comedia que se manifiesta muy cercana en una variada gama de aspectos a las dos que aquí se consideran:

cada piedra un pirámide levanta

y cada flor construye un monumento;

cada edificio es un sepulcro altivo... (vv. 2472-2474)

Como se ha apuntado, ambas damas estaban apenadas en el momento en que se encuentran con las ostensibles calamidades de los maltrechos galanes. Esto hace que ambas experimenten sentimientos parejos de comunión en la desgracia. Dice Hipólita:

Oye lástimas y quejas

de quien aún no te conoce

y llora desdichas tuyas,

que puede ser, si las oyes,

que cobres nuevo valor,

que nuevo espíritu cobres,

37 Se han destacado en cursiva en esta cita y en las siguientes los términos que establecerían relaciones entre ellas.

${ }^{38}$ Las citas se hacen por el texto que publicaré en breve, cuya base es el de la Quinta parte de Comedias de D. Pedro Calderón de la Barca, Barcelona, Antonio la Cavallería, 1677, fols. 142v-163v. En Vega García-Luengos, 2005, pp. 252 y ss., pueden verse los paralelismos que los textos citados de esta comedia establecen con comedias de Calderón. 
que es vida de un desdichado

hallar quien sus penas llore... (p. 582)

Doña Sol se expresa así:

Qué presto, (oh, confusión mortal!, qué presto

a la tristeza mía

diste consuelo con decir que había

otro más desdichado.

Ninguno desconfie de su estado,

pues si posible fuera

trocar uno desdichas, cuando viera

lo que en el mundo pasa,

las suyas propias se volviera a casa. (vv. 120-128)

Hipólita ofrece este tipo de consuelo a don Álvaro, mientras que Sol se lo propone a sí misma, y su planteamiento está aún más cerca del de Rosaura al encontrarse con Segismundo al comienzo también de La vida es sueño:

Solo diré que a esta parte

hoy el cielo me ha guiado

para haberme consolado,

si consuelo puede ser

del que es desdichado ver

a otro que es más desdichado. (vv. 247-252)

Poco más adelante, Laura advierte a Hipólita de la calidad de Álvaro de Viseo, porque lo ha oído quejarse de la Fortuna:

Quejarse de la fortuna

ningún hombre humilde sabe,

porque en su pecho no cabe

sino una queja importuna

llorada rústicamente (p. 594)

Es el mismo planteamiento que Ramiro se hace en Cómo se comunican, cuando oye lamentarse a doña Elvira, la reina de Toro, disfrazada de campesina: 
Sin duda se encierra aquí más que el traje manifiesta no es mujer humilde esta, pues sabe quejarse así. (vv. 1039-1041)

En el segundo acto de Saber del mal, Hipólita habla de amor de "palacio», de amor "cortés», con don Álvaro de Viseo:

Álvaro Porque el amor que se atreve

a palacio, no es amor.

HipÓLITA

Álvaro

¿Pues qué?

Una deidad que mueve, una estrella que arrebata, una inclinación que vence, una humana adoración a lo hermoso solamente, un respeto a lo divino que ni desea ni quiere más premio que solo amor.

HIPÓLITA $\quad$ ¿Y entre ese respeto y ese temor, esa adoración que arrebata y que suspende, entre esa deidad que inclina en palacio no puede haber quien quiera esperando? (p. 620)

También en la segunda jornada de Cómo se comunican, doña Elvira, la reina de Toro, disfrazada de pastora, se encuentra con Enrique, disfrazado de campesino, y se confiesan su amor, que tiene las mismas características que el del anterior fragmento, e incluso, se explica con las mismas palabras:

ENRIQUE Tened la voz, que, aunque con rústico traje, será tan cortés mi amor que amaré sin esperanza, como los amores son de palacio: solamente una humana admiración 
a lo hermoso sin deseo

de la vitoria mayor.

Doña Elvira Pues a vuestro amor licencia

doy, con esa condición.

ENRIQUE Yo con la misma la aceto. (vv. 1919-1930)

Del parentesco entre ambos pasajes no cabe ninguna duda. Por azar es prácticamente imposible llegar a esa identidad de expresiones. El mejor ajuste de la escena en Cómo se comunican puede considerarse como indicio de su prioridad cronológica con relación a Saber del mal $y$ el bien, que podría haberse aprovechado de lo escrito anteriormente. Dejemos este apunte para un poco más adelante.

CÓMO SE COMUNICAN DOS ESTRELLAS CONTRARIAS, UN NUEVO TESTIMONIO DE REESCRITURA

Son bastantes y de diverso carácter los aspectos apuntados que relacionan Saber del mal con Cómo se comunican, tanto por lo que se refiere al desarrollo de la acción como al tratamiento de los personajes y a sus formas de hablar. Pero hay otro nexo muy relevante entre ellas: también Cómo se comunican ha explotado creativamente una comedia de Lope, Las almenas de Toro, escrita hacia 1615, y publicada en la Parte XIV (Madrid, Juan de Cuesta / Miguel de Siles, 1620), de la que debe considerarse reescritura.

Cómo se comunican y Saber del mal y el bien serían, por lo tanto, reelaboraciones, muy cercanas en el tiempo, de comedias de historia medieval española escritas por Lope de Vega, y publicadas años antes de su reescritura en dos de sus partes.

Las características de la reacomodación de la pieza previa de Lope son semejantes: reducción de personajes y episodios, mayor trabazón de cuanto se dice y hace. La obra ofrece una vuelta de tuerca al tratamiento novelesco y lírico de la acción protagonizada por doña Elvira que había dado ya Lope, dejando las hazañas bélicas zamoranas como fondo del que únicamente se habla, y poco.

Con mayor nitidez que en Saber del mal, Cómo se comunican acusa un afán por parte del autor de medir fuerzas con Lope en su propio terreno y con sus propias armas. Esta impresión se ve reforzada por la existencia en ella de un personaje llamado Belardo. Como es bien sa- 
bido, este es el nombre del alter ego poético de Lope de Vega en un buen número se obras. En la que analizamos se le caracteriza de "vejete» en la relación de dramatis personae del encabezamiento, lo que no deja de ser un nuevo indicio de la significación que proponemos.

Aparte de esta idea de emulación, la presencia de Belardo es una nueva pista que nos lleva a pensar en Calderón como autor: hasta donde he podido averiguar, es el único escritor teatral de los identificados fidedignamente que da a algunos de sus personajes un nombre de tan clara asociación al Fénix ${ }^{39}$. Dos son las obras: El pintor de su deshonra (1649-1650) y El alcaide de sí mismo (1627), que debió de ser compuesta en fecha muy próxima a la de Cómo se comunican, y de la que nos ocuparemos en seguida.

Al tiempo que Calderón se aprovechaba de las comedias de Lope en los dos casos que contemplamos (en uno con seguridad y con altísimo grado de probabilidad en el otro), se reaprovechaba también a sí mismo. Este tipo de reescritura, consistente en la reutilización de microsegmentos, decíamos, está continuamente presente en Calderón (no me atrevo a decir si en mayor grado que en las de otros dramaturgos), siendo más intensa entre textos cercanos cronológicamente.

\section{EL ALCAIDE DE SÍ MISMO: MÁS CASOS DE REUTILIZACIÓN CALDERONIANA}

Las conexiones de Saber del mal y Cómo se comunican con La vida es sueño son evidentes: bastará ahora recordar trances que han ido apareciendo en este ensayo: la caída de Rosaura, su encuentro con el infelice Segismundo, cuyas desdichas mayores consuelan las suyas, etc. Quiero ahora detenerme en las relaciones que establecen las tres con El alcaide de sí mismo, de la que consta que fue representada en Palacio antes del 22 de febrero de 1627, fecha en que Tomás Fernández recibió el pago por ello ${ }^{40}$. Sería, por tanto, anterior a Saber del mal.

${ }^{39}$ Belardo se llama también un personaje campesino de Del rey abajo, ninguno, comedia de autoría desconocida, a pesar de que se le ha venido atribuyendo a Rojas Zorrilla. Su relación con el Fénix es aún más clara que en los casos de Calderón.

40 Shergold y Varey, 961, p. 275. La primera edición fechada es la de El mejor de los mejores libros (1651, pp. 348-386), con el título de La guarda de sí mismo. Hay otras ediciones en partes y sueltas a lo largo del siglo XVII. Se la incluyó en la Parte VIII de las comedias del escritor (1684). 
La obra comienza con el protagonista, el príncipe de Sicilia Federico, llegando acompañado de su criado Roberto a un lugar del monte donde no pueden seguir a caballo:

luego, que nos hallamos

en un monte, y que en él los dos estamos, el caballo perdido,

tú cansado, yo armado y sin vestido... (p. 804)

Como Rosaura y Clarín en La vida es sueño:

Hipogrifo violento,

que corriste parejas con el viento,

¿dónde...

... al confuso laberinto

de esas desnudas peñas te desbocas,

te arrastras y despeñas?

Quédate en este monte,

donde tengan los brutos su Faetonte... (vv. 1-10)

Y doña Elvira en Cómo se comunican:

Al pie destos montes altos

rendido el caballo dejo,

tan liberal de su sangre

como avaro de su aliento,

Quédate, noble animal... (vv. 329-345)

La reina de Toro dice a continuación que su desdicha se ha transmitido al animal:

... que suele heredar un bruto

la desdicha de su dueño... (vv. 351-352)

Idea paralela a la que en otro momento expresa un personaje de El alcaide de sí mismo:

... pues parece que el enojo

heredaban de sus dueños... (p. 806) 
Federico y Roberto apuntan notas sobre el lugar y la hora de su descabalgamiento:

... este monte,

término al parecer deste horizonte...

que ya del sol la lumbre

da el primero perfil a aquella cumbre. (p. 805)

que recuerdan las de Rosaura y Clarín en La vida es sueño:

Mas ¿qué haremos, señora,

a pie, solos, perdidos y a esta hora

en un desierto monte,

cuando se parte el sol a otro horizonte? (vv. 45-48)

y las de doña Elvira en Cómo se comunican:

Mas ¿dónde voy por aquí?

¿Qué ásperos montes son estos,

........

¿Qué haré en esta soledad, y más cuando considero

que agonizando entre sombras

el día se está muriendo,

y el sol con tan poca fuerza

hiere el horizonte nuestro...? (vv. 361-378)

Federico esconde entre ramas sus armas y armadura para ocultar su calidad:

Siguiendo tu consejo,

las duras armas en el monte dejo.

Desnudo iré moviendo

a compasión las piedras... (p. 805)

Como doña Elvira, que trueca su ropa con la de una campesina:

por estos vestidos temo

ser conocida y venir

a gran desdicha por ellos. 
Truécamelos a un sayal tuyo...

... que podré

en traje humilde y gracioso

pasar donde me llevare

mi destino. (vv. 486-498) (1 $^{4}$

Federico se hará pasar por mercader de joyas al que han robado unos salteadores:

Un mercader rico era,

........

Yendo, pues, por ese monte,

salió una pequeña tropa

de bandoleros, que en él

la hacienda y la vida roban.

Entregué mi hacienda toda.

Y pensando que guardaba

mi vestido algunas joyas,

(que usar mercaderes suelen

de invenciones cautelosas),

el vestido me quitaron... (p. 808)

Como Enrique de Borgoña en Cómo se comunican:

Un mercader soy de piedras,

[iba] a Santiago,

por un voto; donde aleves,

por robarme algunas joyas,

........

dos amigos y parientes

me dejaron como viste. (vv. 897-915)

41 Este «destino» no puede por menos que evocar en el lector el de las palabras de Rosaura en el comienzo de La vida es sueño: "que yo, sin más camino / que el que me dan las leyes del destino / [...] / bajaré la cabeza enmarañada / de este monte..." (vv. 11-15). 
Federico se encuentra con una dama triste, Elena, que se ha retirado a ese lugar de Belflor para consolarse de la muerte de su hermano Pedro Esforcia, al que precisamente el príncipe de Sicilia ha dado muerte. El encuentro entre desdichados da pie para que ella declare que desdichas consuelan desdichas:

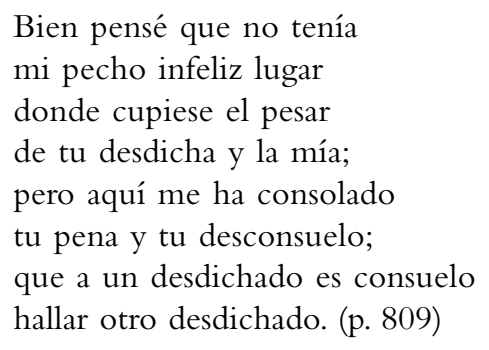

que es idea paralela a las que, en términos semejantes también, expresan Rosaura a propósito de Segismundo en La vida es sueño (vv. 247-252), Hipólita de Álvaro de Viseo en Saber del mal (p. 582), y Sol de Enrique de Borgoña en Cómo se comunican (vv. 120-128), según se vio en los pasajes citados más arriba.

Cuando Elena entra en escena por primera vez, acaba de dejar el caballo y manda a uno de sus acompañantes que lleve un recado a Miraflor:

En tanto que esos caballos, veloces hijos del viento, pagan en cristal y nieve las esmeraldas del suelo... (p. 805)

Lo que se da la mano con otro pasaje de Saber del mal, en el que una de las damas, Jacinta, dice:

Aquí puedes descansar en tanto que los veloces caballos, envidia hermosa de Flegón, de Etón y Etonte, pagan en coral y nieve, nieve, coral, fruta y flores. (p. 579) 
La misma imagen - los caballos pagan o agradecen con sudor y espuma la hierba y el agua que comen y beben - se encuentra en boca de Ramiro en Cómo se comunican:

Ata, Nuño, esos caballos a un tronco, y en la espesura de esa fuente hermosa y pura puedes un rato dejallos, donde si en yerbas ofrecen esmeraldas estos prados, ellos de espuma bañados, en cristales agradecen el beneficio... (vv. 173-180)

Más adelante, Federico decide acogerse al amparo que Elena le ofrece:

La merced que me ofrecéis de vivir con vos aceto.

([Ap.] Aquí viviré secreto.) Sirviéndoos; que bien sabéis que un hombre que rico ha sido dobla en su tierra el dolor, pues vive pobre mejor adonde no es conocido. (p. 809)

La razón por que lo hace es la misma que en Cómo se comunican arguye Enrique de Borgoña a la pregunta de Sol acerca de dónde tiene pensado ir una vez que se ha curado, y que le incita a aceptar la invitación que Sol le formulará de trabajar para su tío:

Adonde pueda

vivir pobre y tristemente

no conocido de nadie.

Porque hombre que no puede

llegar a tener caudal

tan grande como el que pierde

adonde no es conocido

vive mejor, porque suele

ser verdugo la memoria 
cuando los testigos tiene de las dichas que perdió a todas horas presentes. (vv. 917-928)

Compruébese que el v. 923 es idéntico y el 924 muy cercano a otros del pasaje citado de El alcaide de sí mismo, lo que se convierte en otro indicio importante para la atribución de la comedia que protagonizan Sol, Elvira y Enrique.

Consciente de que Cómo se comunican está necesitada de acumular cuantos más indicios mejor para que se la considere cercana al arte de Calderón, señalaré un paralelismo más, estrechísimo, con El alcaide de sí mismo. En esta obra, según se acaba de apuntar, Elena se ha retirado a Belflor para consolar la pena de la muerte de su hermano Pedro Esforcia. Los labradores delegan en uno de ellos, Benito, que le dé el pésame en nombre de todos. Es Antona quien formula el encargo:

\author{
Benito, advierte que ahora \\ tú, por ser el más erguido, \\ más calletrudo y sabido, \\ tienes de dar a Señora \\ el pésame. (p. 807)
}

Lo que este cumplirá con un discurso jocoso lleno de despropósitos. En Cómo se comunican, los campesinos eligen a Jaques, criado de Enrique, que se hace pasar por labrador, para que pida a los amos que les den la bendición antes de partir para la siega. Las palabras de Dominga son:

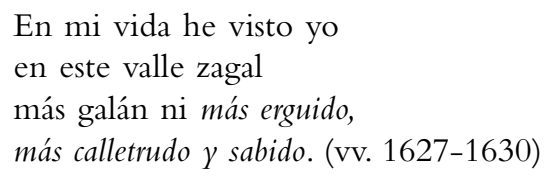

No sólo las situaciones son paralelas, sino que se usan, y en el mismo orden, los mismos adjetivos; que, por otra parte, no son nada comunes: «erguido», «calletrudo» y «sabido». Especialmente peculiar es el central: un derivado de "calletre» (según Autoridades, «juicio, capacidad, entendimiento, discurso o imaginación vehemente...», es voz «jocosa»), con la palatización de la consonante líquida propia del sayagués 
que usan en las comedias áureas los villanos graciosos; de «calletre», "calletrudo», como de «miembro», el gongorino «membrudo». Solo está atestiguado en Calderón.

Estas pequeñas reutilizaciones pueden ser útiles, además, para ayudar a poner orden cronológico. La mayor propiedad del pasaje de $E l$ alcaide de sí mismo apunta hacia su anterioridad. En este caso, a Jaques los despropósitos no le salen espontáneamente —él es un villano fingido - sino que debe impostar la torpeza del campesino; lo que quita fuerza y gracia a la escena.

Según este indicio, Cómo se comunican se habría escrito con posterioridad a El alcaide de sí mismo: sería, por lo tanto, posterior a 1627. Pero, a su vez, como se vio anteriormente, contiene una escena, en la que los protagonistas hablan sobre las condiciones del amor cortés («amor de palacio»), que encuentra aquí mejor acomodo que en la paralela de Saber del mal, de la que nos consta que estaba escrita en 1628. Así pues, según estos indicios, Cómo se comunican habría que situarla entre 1627-1628. Lo que no entra en contradicción con las pautas métricas que se derivan de los análisis de Hilborn (1938).

$\mathrm{Y}$ debe recordarse, en fin, el motivo primero por el que El alcaide de sí mismo se ha traído a colación aquí: la presencia en ella, al igual que en Cómo se comunican, de un campesino al que se le llama Belardo (pp. 818 y 832), aunque en la relación de dramatis personae del comienzo no figure este nombre, sino que está englobado bajo el término «Labradores».

\section{Como CONCLUSIÓN}

El «otro Calderón» del que he pretendido hablar es el Calderón reescritor - competitivo - de Lope, y se ha centrado en los dos casos en que más cerca está la posibilidad de asistir al encuentro entre los dos monarcas máximos del teatro áureo español en los campos de batalla textuales. Uno de ellos con seguridad: Saber del mal y el bien hoy por hoy constituye fehacientemente el único testimonio de reescritura calderoniana sobre una comedia de Lope, Las mudanzas de fortuna y sucesos de don Beltrán de Aragón, a la que todavía no se había acercado la crítica, y de la que aquí se ha ofrecido un primer análisis. El otro caso presenta aún mayor interés en lo que se refiere al diálogo entre la obra reescrita, Las almenas de Toro, y la reescritora, Cómo 
se comunican dos estrellas contrarias, y al espíritu de contienda que rige la operación. Señalan a Calderón como autor de esta segunda pieza muchos y fuertes indicios, la mayoría de los cuales consisten en testimonios de un procedimiento de reescritura muy habitual en él: la «reutilización» de lances, imágenes, expresiones. Sin embargo, no forma parte de su repertorio oficial, y va a costar que lo logre. Por el momento, me conformo con que no caiga en el olvido una comedia tan singular. 


\section{Bibliografía}

Alviti, R., I manoscritti autografi delle commedie del Siglo de Oro scritte in collaborazione. Catalogo e studio, Firenze, Alinea Editrice, 2006.

Antonucci, F. y M. Vitse, "Algunas observaciones acerca de las dos versiones de la tercera jornada de La dama duende», Criticón, 72, 1998, pp. 4972.

Armendáriz Aramendía, A., Edición crítica de "El médico de su honra" de Cal derón de la Barca y recepción crítica del drama (apéndice, edición crítica de El médico de su honra atribuido a Lope de Vega), Madrid / Frankfurt, Iberoamericana / Vervuert, 2007.

Balestrino, G. y M. B. Sosa, El bisel del espejo: la reescritura en el teatro contemporáneo español e hispanoamericano, Salta (Argentina), C.I.U.N., 1997.

Barclay, T. B., «Dos Maestros de danzar», en Homenaje a William L. Fichter: estudios sobre el teatro antiguo hispánico y otros ensayos, ed. A. David Kossoff y J. Amor y Vázquez, Madrid, Castalia, 1971, pp. 71-80.

Bonilla y San Martín, A., "Sobre un tomo perdido de Lope de Vega», en Miscelânea de estudos em honra de D. Carolina Michaëlis de Vasconcellos, Coimbra, Imprensa da Universidade, 1933, pp. 101-110.

Calderón de la Barca, P., El alcaide de sí mismo, en Obras completas, t. II, Comedias, ed. Á. Valbuena Briones, Madrid, Aguilar, 1973, pp. 801-834.

- Saber del mal y el bien, en Comedias, I. Primera parte de comedias, ed. L. Iglesias Feijoo, Madrid, Fundación José Antonio de Castro, 2006, pp. 575-662.

- La vida es sueño, ed. M. Rodríguez Cáceres, introducción de R. Navarro, Barcelona, Ediciones Octaedro, 2001.

Coenen, E., «Las atribuciones de Vera Tassis», Castilla. Estudios de Literatura, 0, 2009, pp. 111-133.

Cruickshank, D. W., "La historia del texto de La vida es sueño en el siglo XVII», en G. Vega García-Luengos, G., D. W. Cruickshank y J. M. Ruano de la Haza, La segunda versión de "La vida es sueño» de Calderón, Liverpool, Liverpool University Press, 2000, pp. 11-36.

- Don Pedro Calderón, Cambridge, Cambridge University Press, 2009.

Durán, A., Catálogo general de comedias de los siglos XV a XVIII, Biblioteca Nacional de España, Ms. 21.423/1.

Escudero Baztán, J. M., El alcalde de Zalamea. Edición crítica de las dos versiones (Calderón de la Barca y Lope de Vega, atribuida), Madrid / Frankfurt, Iberoamericana / Vervuert, 1998.

Fajardo, J. I., Disertación sobre los autos sacramentales de don Pedro Calderón de la Barca, Santander, Biblioteca de Menéndez Pelayo, Ms. 209.

González Cañal, R., "Lope, la corte y los "pájaros nuevos”", Anuario Lope de Vega, 8, 2002, pp. 139-162. 
Heaton, J. C., «On La selva confusa, Attributed to Calderón», Publications of the Modern Language Association, 44, 1929, pp. 243-273.

— «Calderón and El mágico prodigioso», Hispanic Review, 19, 1951, pp. 11-36 y 99-103.

Hilborn, H.W., A Chronology of the Plays of D. Pedro Calderón de la Barca, Toronto, The University of Toronto Press, 1938.

Morley, S. G. y C. Bruerton, Cronología de las comedias de Lope de Vega, versión española de M. R. Cartes, Madrid, Gredos, 1968.

Novo Villaverde, Y., «A vueltas con los manuscritos calderonianos: notas para la edición crítica de Saber del mal y del bien», en Estaba el jardín en flor... Homenaje a Stefano Arata, Criticón, 87-88-89, 2003, pp. 577-587.

Paz y Melia, A., Catálogo de las piezas de teatro que se conservan en el departamento de Manuscritos de la Biblioteca Nacional. T. I, Madrid, Blass s. a. Tipográfica, 1934, 2. ${ }^{\mathrm{a}}$ ed.

Pedraza Jiménez, F. B., Calderón. Vida y teatro, Madrid, Alianza Editorial, 2000.

- «De Lope a Calderón. Notas sobre la sucesión en la monarquía dramática», en Calderón de la Barca y la España del Barroco, coord. J. Alcalá Zamora y E. Belenguer, Madrid, Centro de Estudios Políticos y Constitucionales / Sociedad Estatal España Nuevo Milenio, 2001, vol. II, pp. 831-853.

Profeti, M. G., «El último Lope», en La década de oro de la comedia española: 1630-1640. Actas de las XIX Jornadas de teatro clásico de Almagro, ed. F. B. Pedraza y R. González Cañal, Almagro, Festival de Almagro y Universidad de Castilla-La Mancha, 1997, pp. 11-39.

Rozas, J. M., "Texto y contexto de El castigo sin venganza», en Estudios sobre Lope de Vega, Madrid, Cátedra, 1990, pp. 355-383.

Ruano de la Haza, J. M., La primera versión de "La vida es sueño", de Calderón, Liverpool, Liverpool University Press, 1992.

— «Las dos versiones de El mayor monstruo del mundo, de Calderón», Criticón, 72, 1998, pp. 35-47.

Shergold, N. D. y J. E. Varey, «Some early Calderón dates», Bulletin of Hispanic Studies, 38, 1961, pp. 274-286.

Sloman, A. E., "La selva confusa restored to Calderón», Hispanic Review, 20, 1952a, pp. 134-148.

- «El mágico prodigioso: Calderón Defended Against che Charge of Theft», Hispanic Review, 20, 1952b, pp. 212-222.

- The Dramatic Craftsmanship of Calderón, Oxford, The Dolphin Book, 1969.

Torres, J. C., "Adiciones al tema de las citas cervantinas en Calderón: las citas sobre Lope de Vega», Anales cervantinos, 35, 1999, pp. 571-584 y 577580.

Vega, Lope de, Comedias escogidas de Frey Lope Félix de Vega Carpio, ed. J. E. Hartzenbusch, Madrid, M. Rivadeneyra, 1853-1860, 4 vols. 
- Las mudanzas de fortuna y sucesos de don Beltrán de Aragón, ed. G. Pontón, en Comedias de Lope de Vega. Parte III, coord. L. Giuliani, Lérida, Milenio / Universidad Autónoma de Barcelona, 2002, pp. 253-365.

Vega García-Luengos, G., «Imitar, emular, renovar en la comedia nueva: Cómo se comunican dos estrellas contrarias, reescritura "calderoniana" de Las almenas de Toro», Anuario de Lope de Vega, 11, 2005, pp. 243-264.

- «Nuevos aspectos intertextuales de La vida es sueño (con indicios del Calderón extracanónico)», en La dramaturgia de Calderón. Técnicas y estructuras (Homenaje a Jesús Sepúlveda), ed. I. Arellano y E. Cancelliere, Madrid / Frankfurt, Iberoamericana / Vervuert, 2006, pp. 587-608.

- «Consideraciones sobre la configuración del legado de comedias de Calderón», Criticón, 103-104, 2008 (Ejemplar dedicado a La literatura española en tiempos de los novatores. 1675-1726), pp. 249-271.

- «Problemas de atribución y crítica textual en Rojas Zorrilla», en El teatro del Siglo de Oro. Edición e interpretación, Ed. A. Blecua, I. Arellano y G. Serés, Madrid / Frankfurt, Iberoamericana / Vervuert, 2009, pp. 465-489. Vitse, M., «Presentación», Criticón, 72, 1998 (núm. dedicado a Siglo de Oro y reescritura. I: Teatro, ed. M. Vitse), pp. 5-8.

Wilson, E. M., «An early list of Calderón's Comedias», Modern Philology, 60, 2, 1962, pp. 95-102. 